\title{
Increased Risk of Severe Hypoglycemic Events with Increasing Frequency of Non-severe Hypoglycemic Events in Patients with Type 1 and Type 2 Diabetes
}

Seamus Sreenan · Marc Andersen • Brian Larsen Thorsted •

Michael L. Wolden • Marc Evans

To view enhanced content go to www.diabetestherapy-open.com

Received: May 8, 2014 / Published online: July 15, 2014

(c) The Author(s) 2014. This article is published with open access at Springerlink.com

\section{ABSTRACT}

Introduction: Severe hypoglycemic events (SHEs) are associated with significant morbidity, mortality and costs. However, the more common non-severe hypoglycemic events (NSHEs) are less well explored. We investigated the association between reported frequency of NSHEs and SHEs among patients with type 1 diabetes mellitus (T1DM) and type 2 diabetes mellitus (T2DM) in the PREDICTIVE study.

Trial Registration Clinicaltrials.gov \#NCT00659295.

Electronic supplementary material The online version of this article (doi:10.1007/s13300-014-0075-x) contains supplementary material, which is available to authorized users.

S. Sreenan

Department of Endocrinology, Connolly Hospital, Blanchardstown, Dublin 15, Ireland

\section{Andersen}

Statgroup, Fruebjergvej 3, 2100 Copenhagen,

Denmark

B. L. Thorsted · M. L. Wolden ( $\square)$

Novo Nordisk A/S, Vandtaarnsvej 114,

2860 Soeborg, Copenhagen, Denmark

e-mail: mlwo@novonordisk.com

M. Evans

Llandough Hospital, Penlan Road, Penarth South

Glamorgan, Cardiff CF64 2XX, UK
Methods: PREDICTIVE was a global, prospective, observational study. Patients with T1DM $\quad(n=7,420) \quad$ or $\mathrm{T} 2 \mathrm{DM} \quad(n=12,981)$, starting treatment with insulin detemir, reported the number of NSHEs and SHEs experienced during the 4 weeks prior to baseline and follow-up visits (mean 14.4 weeks). Logistic regression was used to determine the odds ratio (OR) of experiencing $\geq 1$ SHE, in patients having 1-4 or $\geq 5$ NSHEs, versus those having 0 NSHEs, while controlling for baseline covariates.

Results: Hypoglycemia rates were lower at follow-up than baseline. At baseline 59.2\% (T1DM) and $18.8 \%$ (T2DM) reported any hypoglycemia and at follow-up 39.5\% (T1DM) and $8.6 \%$ (T2DM). There was a significant $(P<0.0001)$ increase in the odds of $\geq 1$ SHEs with increasing frequency of NSHEs in T1DM and T2DM, for both crude and adjusted estimates. At baseline, in T1DM, ORs for $\geq 1$ SHE were 1.92 and 2.13 for $1-4$ and $\geq 5$ NSHEs, respectively; the corresponding ORs in T2DM were 10.83 and 15.36, respectively. At followup, the ORs for $\geq 1$ SHE were 2.01 and 3.20 (T1DM) and 18.99 and 24.29 (T2DM) for 1-4 and $\geq 5$ NSHEs, respectively. 
Conclusion: A statistically significant association between NSHE and SHE frequency was found in T1DM and T2DM. These data provide a clear rationale for the reduction of hypoglycemic events, regardless of severity, while striving for optimal glycemic control.

Keywords: Diabetes mellitus; Hypoglycemia; Insulin detemir; Non-severe hypoglycemia; Observational studies; Severe hypoglycemia

\section{INTRODUCTION}

Hypoglycemic events are of major clinical importance, adversely affecting health, quality of life, adherence to therapy and workplace productivity [1-6]. They represent a significant clinical concern and source of distress in patients with both type 1 diabetes mellitus (T1DM) and type 2 diabetes mellitus (T2DM) [7-11], both for insulin users as well as for patients using only oral antidiabetic drugs (OADs) [12-15]. Hypoglycemic events or fear of such events has been identified as the major treatment-limiting factors in titrating insulin to optimal glycemic targets in T2DM $[16,17]$. A recent meta-analysis of 13 randomized trials suggested that the harm associated with severe hypoglycemic events (SHEs) could even negate the benefit of intensive glucose reduction [18]. Emergency hospitalizations arising from SHEs represent a considerable economic cost to patients and insurers [19-21]. Despite the clinical consequences of hypoglycemia and the burden it causes to patients and health-care providers, in one large $(n=3,827)$ European survey, $65 \%$ of people with T1DM and $50-59 \%$ of people with T2DM who experienced a non- severe hypoglycemic event (NSHE) rarely or never informed their physician about hypoglycemia; additionally, among all responders, $17 \%$ of those with $\mathrm{T} 1 \mathrm{DM}$ and 21-28\% with T2DM reported not being asked about hypoglycemia by their physician during routine appointments [22]. Clinically, there may be an impression that the lower frequency of hypoglycemia in T2DM means that it is of lesser clinical importance in that type of diabetes; such an interpretation, however, may not adequately characterize the impact of hypoglycemia in T2DM [8, 9, 23].

Given this background, understanding the constellation of factors predisposing to hypoglycemia, and SHEs in particular, is of considerable clinical importance [24]. One of the most consistently reported risk factors for SHEs is a history of prior SHEs [7]. For example, in one observational study of 267 patients with insulin-treated diabetes, statistically significant predictors of hypoglycemia in T1DM included a history of previous hypoglycemia $(P=0.006)$ and co-prescribing of any oral medication $(P=0.048)$ [7]. For T2DM, a history of previous hypoglycemia $(P=0.0001)$ and duration of insulin treatment $(P=0.014)$ were significant. NSHEs, for which third-party assistance is not required, occur far more commonly than SHEs; however, the clinical and economic relevance of such events may be underappreciated, especially in T2DM. In particular, there is a lack of data reflecting the potential association between NSHEs and SHEs.

The aim of this study was to report data on the co-occurrence of NSHEs and SHEs (without inferring a causal relationship between the two) and, using a regression model, to determine which covariates influence the likelihood of experiencing a SHE. 


\section{METHODS}

\section{Subjects}

PREDICTIVE was a global, prospective, openlabel, observational study of more than 20,000 patients with T1DM or T2DM intended to evaluate the safety and efficacy of insulin detemir in routine clinical practice; details of the study design and primary results have been published [25-27]. This secondary analysis reports data on the frequency of NSHEs and SHEs, along with their co-occurrence, in insulin-treated patients with T1DM $(n=7,420)$ or T2DM $(n=12,981)$ from 11 countries (Austria, Czech Republic, Denmark, Finland, Germany, Ireland, Israel, Netherlands, Sweden, Turkey, and the UK). We selected PREDICTIVE (Clinicaltrials.gov \#NCT00659295) for this analysis because it was unique in the systematic way in which NSHEs were recorded and the trial enrolled sufficient numbers of patients to allow analysis of SHEs in people with T2DM. As an observational study, we also believed PREDICTIVE offered the advantage of reflecting real-world practice. The analysis in this article does not involve any new studies of human or animal subjects performed by any of the authors.

\section{Insulin Treatment}

Patients entering this study were prescribed insulin detemir (100 U/ml formulation) by their physician as part of routine clinical care and followed up for a mean period of 14.4 weeks. Patients currently using insulin detemir were ineligible. $75 \%$ of patients with T1DM were using a basal-bolus regimen at baseline, compared with $25 \%$ of those with T2DM. A further $31 \%$ of patients with T2DM were using insulin plus OADs and $27 \%$ used
OADs without insulin. Neutral protamine Hagedorn insulin was the most commonly used basal insulin prior to entering the study (63\% T1DM, 66\% T2DM), followed by insulin glargine (34\% T1DM, 29\% T2DM). All decisions about insulin dose, frequency of dosing and other treatments were at the discretion of the patient's physician.

\section{Hypoglycemic Events}

Patients reported the number of NSHEs and SHEs experienced during the 4 weeks prior to baseline and during a 4-week period prior to the end of their follow-up visit. SHEs were defined as an episode with symptoms of neuroglycopenia, in which the patient was unable to treat himself/herself and third-party intervention was needed, and where the patient had one of the following characteristics: (i) blood glucose $<2.8 \mathrm{mmol} / \mathrm{L}(<50 \mathrm{mg} / \mathrm{dL})$ or (ii) reversal of symptoms after food intake, glucagon or intravenous glucose administration. Confirmed hypoglycemic events where third-party assistance was not required were classified as NSHEs. SHEs were categorized into 0 versus $\geq 1$ in frequency, and NSHEs were classified as $0,1-4$, and $\geq 5$ in frequency, during the two reporting periods.

\section{Statistical Analysis}

Demographic variables and baseline diabetes characteristics were summarized with descriptive statistics. Hypoglycemic events were analyzed by severity and frequency (NSHEs: $0,1-4, \geq 5$ events; SHEs: 0 and $\geq 1$ event). The primary end point of this study was the association between NSHEs and SHEs at baseline and between NSHEs and SHEs at follow-up. Cross-tabulations and the Chisquare test were used to test for statistically 
significant associations between frequencies of NSHE and SHE, for T1DM and T2DM. Unadjusted and adjusted odds ratios (ORs) and 95\% confidence intervals (CIs) for experiencing $\geq 1$ SHEs, in patients having 1-4 and $\geq 5$ NSHEs versus those with 0 NSHEs, were estimated using multivariate logistic regression so that the effect of potential covariates could be taken into account. Covariates for adjusted ORs included age, body mass index (BMI), duration of diabetes, baseline glycosylated hemoglobin $\left(\mathrm{HbA}_{1 \mathrm{c}}\right)$ and gender, which are all potential confounders of the relationship between NSHEs and SHEs. Data were stratified by type of diabetes for all analyses. All analyses were performed using SAS $^{\circledR} 9.3$ Software (SAS Institute Inc., Cary, NC, USA).

\section{RESULTS}

\section{Patients}

Baseline demographics (mean $\pm \mathrm{SD}$ ) of the study population are summarized in Table 1. Glycemic control at baseline was similar for both T1DM and T2DM $\left(\mathrm{HbA}_{1 \mathrm{c}} 8.2 \pm 1.6\right.$ and $8.5 \pm 1.6 \%$, respectively). Glycemic control significantly improved at follow-up which has previously been reported [25]. As might be expected, patients with T1DM were younger and had a longer duration of diabetes and a lower BMI than those with T2DM.

\section{Frequency of Hypoglycemic Events}

The proportion of patients providing data concerning the frequency of hypoglycemic events was high (>90\%) at baseline ( $n=7,399 /$ 7,420 and $n=12,966 / 12,981$, for T1DM and T2DM, respectively) and at follow-up ( $n=6,837 / 7,420$ and $12,368 / 12,981$, for T1DM and T2DM, respectively). Hypoglycemic episodes per patient year have been reported previously [25]. As might be expected, both during the 4-week reporting periods at baseline and at follow-up, a greater proportion of patients with T1DM reported a hypoglycemic event (baseline: T1DM, 4,380/7,399, 59.2\%; T2DM 2,443/12,966, 18.8\%; follow-up: T1DM, 2,702/6,837, 39.5\%; T2DM, 1,062/12,368, $8.6 \%)$. As these data show, the frequency of all hypoglycemic events decreased in both T1DM and T2DM from baseline to follow-up.

With respect to SHEs, the number of patients experiencing SHEs was about threefold greater in T1DM compared with T2DM at baseline (baseline: T1DM, 741/7,399, 10.0\%; T2DM, 445/12,966, 3.4\%; follow-up: T1DM, 145/6,837, 2.1\%; T2DM, 41/12,368, 0.3\%). When stratified by the number of NSHEs $(0,1-4, \geq 5$ NSHEs; Fig. 1), the frequency of SHEs was greater among patients who also reported having NSHEs.

\section{Association Between NSHEs and SHEs at Baseline}

At baseline, there was a statistically significant association between the frequency of NSHEs and SHEs, both for patients with T1DM $(P<0.0001)$ and for those with T2DM $(P<0.0001)$. For patients with T1DM, those who experienced NSHEs had more than twice the odds of experiencing $\geq 1$ SHE, compared with those who experienced 0 NSHEs: unadjusted ORs [95\% CIs] were 2.07 [1.72; 2.49] for 1-4 NSHEs, and 2.31 [1.90; 2.82] for $\geq 5$ NSHE. By comparison, for patients with $\mathrm{T} 2 \mathrm{DM}$, the odds of experiencing $\geq 1$ SHE were $>10-15$ times greater for those who experienced an NSHE, compared to those who did not experience an NSHE in the 4 weeks prior to the study $(\mathrm{OR}=11.09[8.91 ; 13.81]$ for $1-4$ 
Table 1 Baseline characteristics of participants in the PREDICTIVE study

\begin{tabular}{|c|c|c|c|c|}
\hline \multirow{2}{*}{$\begin{array}{l}\text { Characteristic } \\
\text { Gender }\end{array}$} & \multicolumn{2}{|c|}{ Patients with type 1 diabetes $N=7,420$} & \multicolumn{2}{|c|}{ Patients with type 2 diabetes $N=12,981$} \\
\hline & & & & \\
\hline Female $(n, \%)$ & 3,733 & $(50.3)$ & 6,877 & $(53.0)$ \\
\hline Male $(n, \%)$ & 3,684 & $(49.7)$ & 6,101 & $(47.0)$ \\
\hline Missing $(n, \%)$ & 3 & $(0.04)$ & 3 & $(0.02)$ \\
\hline Age, years & $41.4 \pm 16.8$ & & $60.6 \pm 10.8$ & \\
\hline$\leq 55$ years $(n, \%)$ & 5,759 & $(77.6)$ & 4,061 & $(31.3)$ \\
\hline$>55-65$ years $(n, \%)$ & 1,006 & $(13.6)$ & 4,500 & $(34.7)$ \\
\hline$>65$ years $(n, \%)$ & 645 & $(8.7)$ & 4,383 & $(33.8)$ \\
\hline Missing $(n, \%)$ & 10 & $(0.1)$ & 37 & $(0.3)$ \\
\hline Diabetes duration, years & $16.4 \pm 12.5$ & & $11.2 \pm 7.5$ & \\
\hline $0-5$ years $(n, \%)$ & 1,628 & $(21.9)$ & 2,972 & $(22.9)$ \\
\hline$>5-10$ years $(n, \%)$ & 1,253 & $(16.9)$ & 4,153 & $(32.0)$ \\
\hline$>10-20$ years $(n, \%)$ & 2,119 & $(28.6)$ & 4,443 & $(34.2)$ \\
\hline$>20$ years $(n, \%)$ & 2,320 & $(31.3)$ & 1,292 & $(10.0)$ \\
\hline Missing $(n, \%)$ & 100 & $(1.4)$ & 121 & $(0.9)$ \\
\hline Body mass index, $\mathrm{kg} / \mathrm{m}^{2}$ & $25.2 \pm 4.5$ & & $30.9 \pm 5.9$ & \\
\hline$\leq 25 \mathrm{~kg} / \mathrm{m}^{2}(n, \%)$ & 3,917 & $(52.8)$ & 1,602 & $(12.3)$ \\
\hline$>25-30 \mathrm{~kg} / \mathrm{m}^{2}(n, \%)$ & 2,469 & $(33.3)$ & 4,772 & $(36.8)$ \\
\hline$>30-35 \mathrm{~kg} / \mathrm{m}^{2}(n, \%)$ & 738 & $(10.0)$ & 3,813 & $(29.4)$ \\
\hline$>35 \mathrm{~kg} / \mathrm{m}^{2}(n, \%)$ & 200 & $(2.7)$ & 2,657 & $(20.5)$ \\
\hline Missing $(n, \%)$ & 96 & $(1.3)$ & 137 & $(1.1)$ \\
\hline Baseline $\mathrm{HbA}_{1 \mathrm{c}} \%$ & $8.2 \pm 1.6$ & & $8.5 \pm 1.6$ & \\
\hline$\leq 7.5(n, \%)$ & 2,483 & $(33.5)$ & 3,289 & $(25.3)$ \\
\hline$>7.5-8.0(n, \%)$ & 995 & $(13.4)$ & 1,782 & $(13.7)$ \\
\hline$>8.0-9.0(n, \%)$ & 1,707 & $(23.0)$ & 3,203 & $(24.7)$ \\
\hline$>9.0(n, \%)$ & 1,886 & $(25.4)$ & 3,698 & $(28.5)$ \\
\hline Missing $(n, \%)$ & 349 & $(4.7)$ & 1,009 & $(7.8)$ \\
\hline
\end{tabular}

Data are mean $\pm S D$, unless otherwise indicated

$H b A_{1 c}$ glycosylated hemoglobin

NSHEs, and OR $=15.36[11.47 ; 20.57]$ for $\geq 5$ NSHEs).

In the multiple logistic regression model, which was adjusted for gender, age, $\mathrm{BMI}, \mathrm{HbA}_{1 \mathrm{c}}$, and diabetes duration, NSHEs were still consistent predictors of SHEs in both T1DM and T2DM. Several covariates had a statistically significant effect on the parameter estimates 


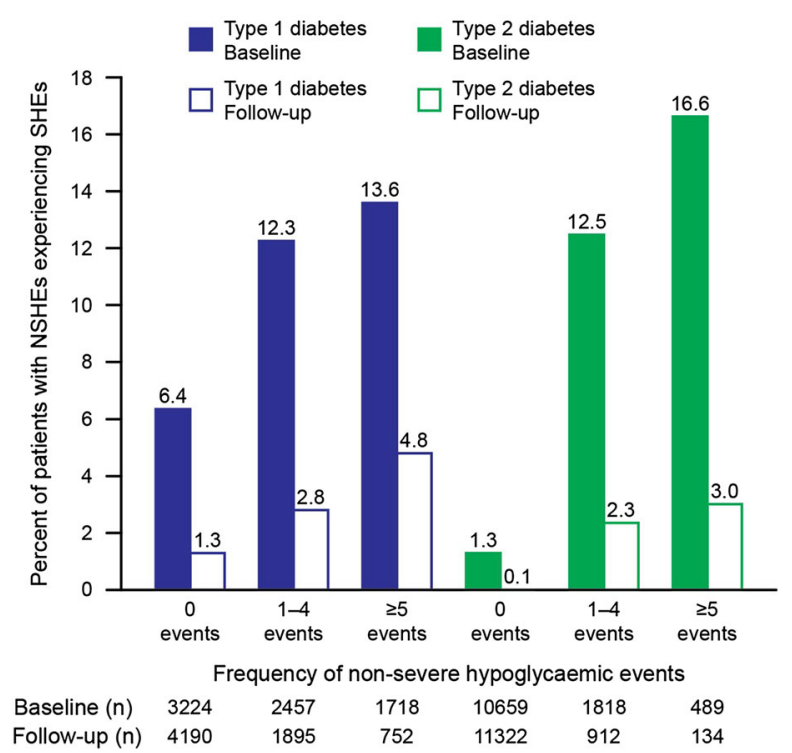

Fig. 1 Hypoglycemic events recorded during 4 weeks before baseline and 4 weeks before follow-up, for type 1 and type 2 diabetes mellitus, in the PREDICTIVE study. NSHE non-severe hypoglycemic event, $S H E$ severe hypoglycemic event

(Fig. 2). For T1DM, greater BMI was associated with slightly decreased odds of SHEs $(P=0.0341)$, and longer duration of diabetes was associated with increased odds of SHEs $(P<0.0001)$. For T2DM, increasing BMI was associated with significantly lower odds of SHEs $(P=0.0017)$. However, adjustment for potential confounding using these covariates had a negligible effect on the parameter estimates for odds of $\geq 1$ SHE in patients with T1DM or T2DM compared to the unadjusted estimates.

\section{Association Between NSHEs and SHEs at Follow-up}

At follow-up, after a mean of 14.4 weeks of therapy using insulin detemir, there was a statistically significant association between the frequency of NSHEs and the occurrence of SHEs, both for patients with T1DM $(P<0.0001)$ and those with T2DM $(P<0.0001)$. For patients with
T1DM, those who experienced NSHEs had $>2$ times the odds of also experiencing a SHE, compared with those who experienced 0 NSHEs $(\mathrm{OR}=2.21[1.51 ; 3.22]$ for $1-4$ NSHEs vs. 0 NSHEs, and $\mathrm{OR}=3.78[2.47 ; 5.80]$ for $\geq 5$ NSHE vs. 0 NSHEs [values are unadjusted ORs and 95\% CIs]). For patients with T2DM, the odds of experiencing a SHE were $>15-20$ times greater for those who experienced an NSHE, compared to those who did not experience an NSHE $(\mathrm{OR}=16.65(8.66 ; 32.02)$ for $1-4$ NSHEs vs. 0 NSHEs, and $\mathrm{OR}=21.74[7.17 ; 65.91]$ for $\geq 5$ NSHE vs. 0 NSHEs).

Finally, $9 \%$ of T1DM and $3 \%$ of T2DM patients who experienced a SHE at baseline also experienced an event at follow-up. In $\begin{array}{lllll}\text { contrast } & 1 \% & \text { (T1DM) and } & 0.2 \% & \text { (T2DM) }\end{array}$ experienced a SHE at follow-up without experiencing a SHE at baseline.

In the multiple logistic regression model, longer duration of diabetes was associated with an increased risk of SHEs $(P=0.004)$ in T1DM, whereas in T2DM, none of the covariates in the adjusted model were statistically significant. The odds of experiencing a SHE with increasing frequency of NSHEs remained statistically significant $(P<0.0001)$ and increased slightly in magnitude when adjusted for confounders, for either T1DM or T2DM (Fig. 3). In T1DM, adjusted ORs for experiencing a SHE again changed very little compared to unadjusted estimates (Fig. 3). However, in T2DM, the association between NSHEs and SHEs was further strengthened, compared to unadjusted estimates, after adjusting for potential confounders (Fig. 2).

\section{DISCUSSION}

These observational data, from a large cohort of patients with T1DM or T2DM in 11 countries (PREDICTIVE study) using insulin detemir in a 


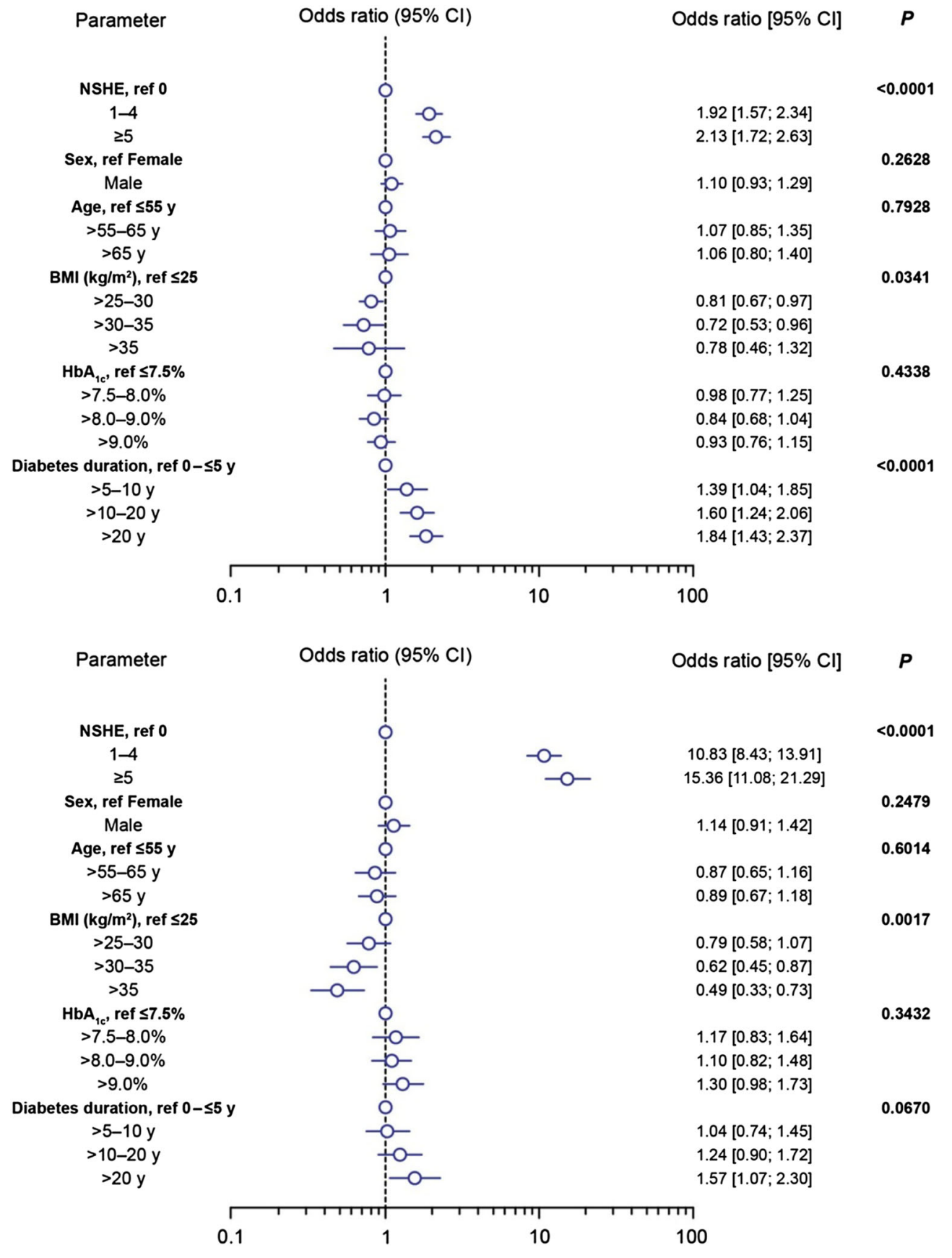

Fig. 2 Adjusted odds ratio estimates for experiencing $\geq 1$ SHEs for T1DM (top) and T2DM (bottom), at baseline in interval, $H b A_{1 c}$ glycosylated hemoglobin, NSHE non-severe hypoglycemic event, $S H E$ severe hypoglycemic event, TIDM type 1 diabetes mellitus, T2DM type 2 diabetes mellitus

setting of routine care provide confirmation of a strong association between the occurrence of frequency of NSHEs (i.e., 0, 1-4 and $\geq 5$ events), NSHEs and SHEs. Importantly, the odds of both at baseline and at follow-up. This supports the notion that NSHEs could predispose to experiencing $\geq 1$ SHE increased with increasing SHEs, a concept that is supported by the 


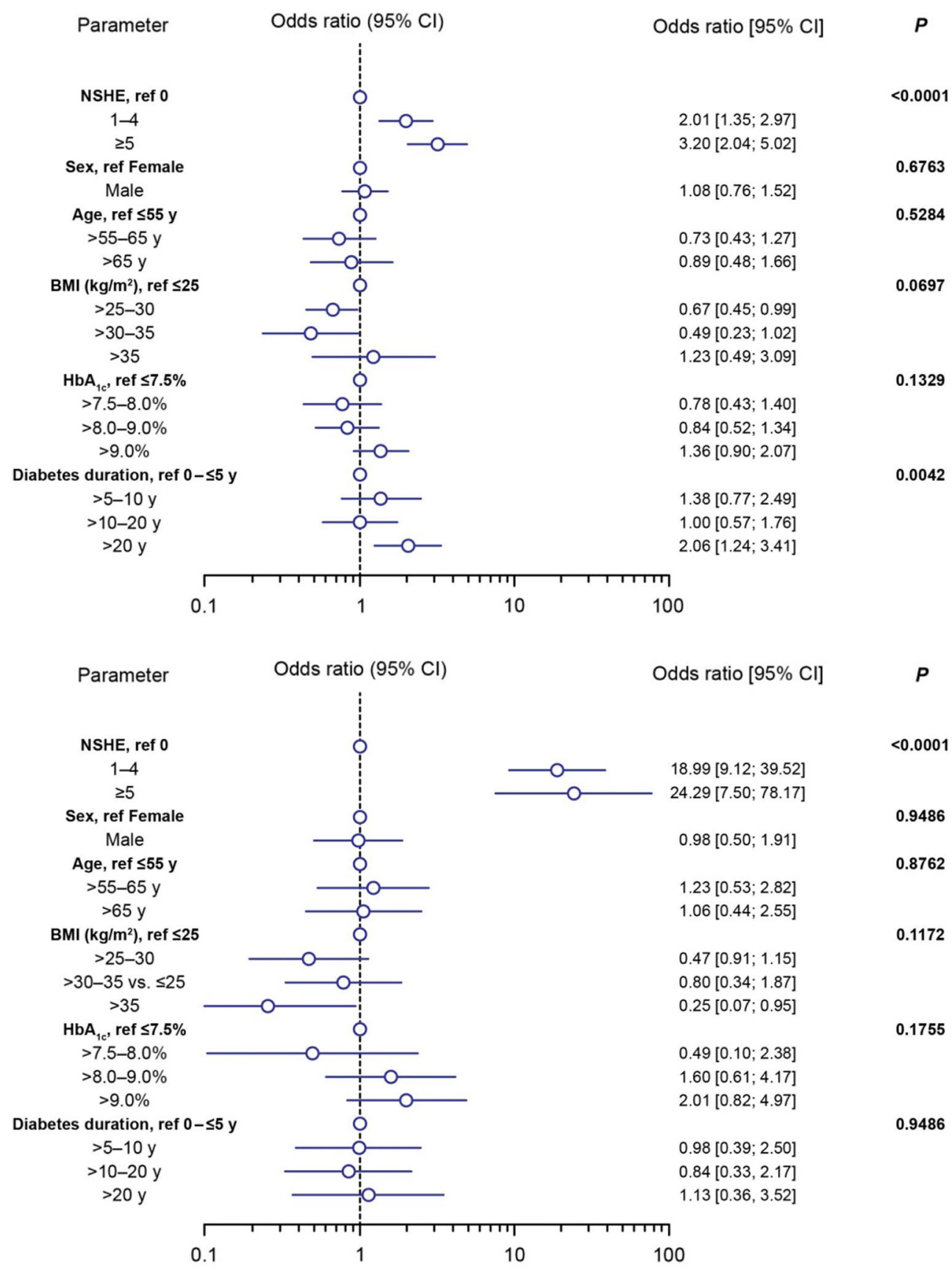

Fig. 3 Adjusted odds ratio estimates for experiencing $\geq 1$ SHEs for T1DM (top) and T2DM (bottom), at follow-up in the PREDICTIVE study. $P$ values are for the covariate named on the left. BMI body mass index, $C I$ confidence

relationship between NSHEs and SHEs being maintained despite adjustment for potential confounders, both in patients with T1DM and T2DM. interval, $H b A_{1 c}$ glycosylated hemoglobin, NSHE non-severe hypoglycemic event, $S H E$ severe hypoglycemic event, T1DM type 1 diabetes mellitus, T2DM type 2 diabetes mellitus

As previously reported for the PREDICTIVE study, the absolute frequency of NSHEs and SHEs all decreased significantly from baseline $(P<0.0001)$ [25]. Despite this decrease in 
frequency of hypoglycemic events following treatment with insulin detemir, the association between the frequency of NSHEs and SHEs in this secondary analysis remained statistically significant. Because of the very high level of reporting ( $>90 \%)$ and collection of data over a comparatively short period of time (4week periods), reporting fatigue should have been minimized. Although the odds of experiencing a SHE in subjects with NSHEs were actually higher at follow-up, it is likely that with fewer patients experiencing hypoglycemia, events were concentrated within the most vulnerable individuals, with the association between NSHEs and SHEs thereby becoming even stronger. Interestingly, the advantage of T2DM with respect to having lower frequency of SHEs (compared to T1DM) was tempered once any NSHE was reported.

An interesting finding was that the effect of increasing frequency of NSHEs on odds of having $\geq 1$ SHEs was much greater in T2DM than in T1DM, being at least fivefold greater at baseline and more than eightfold greater at follow-up. The odds of $\geq 1$ SHE were increased from 10- to 25-fold for patients with T2DM who reported NSHEs, whereas the odds of $\geq 1$ SHE increased only about 2- to 3-fold for patients with T1DM who reported NSHEs (Figs. 2, 3). This further highlights the relevance of hypoglycemia in T2DM, which, as others have noted [8], may be underappreciated and highlights the need to adopt strategies directed toward the reduction of both severe and non-severe hypoglycemia in patients with both T1DM and T2DM. Furthermore, our analysis indicates that overweight people with T2DM (BMI $>35 \mathrm{~kg} / \mathrm{m}^{2}$ ) seemed to have a lower frequency of both NSHE and SHE which can be explained by increasing insulin resistance.

Potential mechanisms that may account for the association between NSHEs and SHEs observed in our analysis may relate to the effect of recurrent symptomatic hypoglycemia with respect to blunted subsequent counterregulatory hormone secretion [28]. Our data may also reflect an extension of observations from the Action In Diabetes And Vascular Disease: Preterax And Diamicron Modified Release Controlled Evaluation (ADVANCE; ClinicalTrials.gov \#NCT00145925) study [15], suggesting a clustering of hypoglycemia in susceptible individuals.

This study supports other data evaluating the relevance of non-severe hypoglycemia. Indeed, NSHEs have a significant detrimental effect on patients' quality of life, adherence to prescribed insulin doses and workplace productivity [1]. This was recently demonstrated from a survey of people with diabetes in the USA, UK, Germany and France, where over a 1-month period, mean losses in workplace productivity were estimated to range from \$US15.26-93.47 in relation to each NSHE. The cost of hospital treatment of a SHE is considerably greater. In one study of 639 patients in Germany, Spain and the UK, costs per SHE averaged \$US304-693 per event [20].

\section{Limitations}

Data concerning the incidence of either NSHEs or SHEs in this study must be interpreted with the understanding that hypoglycemic events were only reported during a 4-week period at baseline and a 4-week period at the end of the study. Due to the study design, it is not possible to determine whether increased frequency of NSHEs precedes the occurrence of SHEs and whether a causal relationship exists. It is thus possible that our observations represent an indication bias translating into a clustering of hypoglycemia episodes in people predisposed to those events. To address such a consideration, it would be interesting to investigate the temporal 
relationship between NSHEs and SHEs. It is also possible that unrecorded clinical or sociodemographic factors that influence the risk of overall hypoglycemia could potentially bias the results of this analysis. However, it should be noted that in this study, we did measure and control for factors that have been reported elsewhere as important confounding variables [7]. Another potential confounding factor in this analysis is the influence of reporting bias, since the data rely on patient-reported hypoglycemic events. Self-monitored blood glucose values were not available for any patients with NSHEs. Thus, it is possible that some of these patients may have had blood glucose $<2.8 \mathrm{mmol} / \mathrm{L}$. However, in this study, the key distinguishing factor between SHEs and NSHEs was the requirement for assistance by a third party. Finally, at follow-up all patients were treated with insulin detemir which could influence the generalizability of the association found in this study.

The number of SHEs was too small to allow stratification and analysis according to the baseline regimen in T2DM. However, the diversity of baseline regimens is reflective of routine clinical practice, thus perhaps increasing the generalizability of our results. Logistic regression (dichotomous outcome and hence ORs) were used instead of Poisson regression (counts) for several reasons. Very few patients had $>1$ SHE, and the time period was the same for all patients and comparatively short; therefore a Poisson model was not appropriate and results would have been very similar to modeling a dichotomous outcome. The total number of SHEs may not have been determined precisely. For these reasons, we focused our analysis on whether or not $\geq 1$ SHE occurred and did not attempt to model the number of SHEs. Since there is a considerable degree of variability in the definition of hypoglycemia, combined with the observation that the definition of SHEs versus NSHEs is not always explicit or clear between studies [5], future studies with a consistent definition of hypoglycemia are required to further explain the relationship between NSHEs and SHEs.

\section{CONCLUSION}

NSHEs appear to be an important factor consistently and independently associated with the risk of SHEs among patients with both T1DM and T2DM. The magnitude of this risk association was more pronounced for patients with T2DM, highlighting the importance of non-severe hypoglycemia both in patients with T1DM and T2DM. Regardless of whether NSHEs are a prelude to, or simply a marker for, SHEs (which in the worst case may be fatal), it is essential that physicians obtain an accurate account of their patients' hypoglycemic experience during consultations. These results thus provide both clinical and economic rationale for making every effort to reduce the frequency of hypoglycemic events, regardless of severity, in patients with T1DM or T2DM.

\section{ACKNOWLEDGMENTS}

This study and the article processing charges were sponsored by Novo Nordisk and registered at clinicaltrials.gov. All named authors meet the ICMJE criteria for authorship for this manuscript, take responsibility for the integrity of the work as a whole and have given final approval to the version to be published. The authors are grateful to Gary Patronek and Mark Nelson of Watermeadow Medical (supported by Novo 
Nordisk) for writing assistance and submission assistance.

Conflict of interest. Prof. Seamus Sreenan has acted as advisory board member and speaker for Novartis, Novo Nordisk, Eli Lilly and Company, Merck Sharpe \& Dohme, BristolMyers Squibb and sanofi-aventis; as a speaker for Glaxo Smith Kline and AstraZeneca; and has received grants from Novo Nordisk, Eli Lilly and Company, Sanofi-Aventis, AstraZeneca and Bristol-Myers Squibb. Marc Andersen is Consultant for Novo Nordisk A/S. Brian L. Thorsted is an employee and shareholder of Novo Nordisk A/S. Michael Lyng Wolden is an employee and shareholder of Novo Nordisk A/S. Marc Evans has received research awards, honoraria and consultancy fees from Novo Nordisk, Sanofi-Aventis, Merck Sharpe \& Dohme, Novartis, Eli Lilly and Company, and Takeda. All authors contributed to design, conduct/data collection, analysis and interpretation of data and to the writing and final approval of this article.

Compliance with ethics guidelines. The analysis in this article is based on previously conducted studies and does not involve any new studies of human or animal subjects performed by any of the authors.

Open Access. This article is distributed under the terms of the Creative Commons Attribution Noncommercial License which permits any noncommercial use, distribution, and reproduction in any medium, provided the original author(s) and the source are credited.

\section{REFERENCES}

1. Brod M, Christensen T, Thomsen TL, Bushnell DM. The impact of non-severe hypoglycemic events on work productivity and diabetes management. Value Health. 2011;14(5):665-71.

2. Barendse S, Singh H, Frier BM, Speight J. The impact of hypoglycaemia on quality of life and related patient-reported outcomes in type 2 diabetes: a narrative review. Diabet Med. 2012;29(3): 293-302.

3. Brod M, Christensen T, Bushnell DM. Impact of nocturnal hypoglycemic events on diabetes management, sleep quality, and next-day function: results from a four-country survey. J Med Econ. 2012;15(1):77-86.

4. Leiter LA, Yale J-F, Chiasson J-L, Harris S, Kleinstiver $\mathrm{P}$, Sauriol L. Assessment of the impact of fear of hypoglycemic episodes on glycemic and hypoglycemia management. Can J Diab. 2005;29:186-92.

5. Frier BM. How hypoglycaemia can affect the life of a person with diabetes. Diabetes Metab Res Rev. 2008;24(2):87-92.

6. Peyrot M, Barnett AH, Meneghini LF, SchummDraeger PM. Insulin adherence behaviours and barriers in the multinational global attitudes of patients and physicians in insulin therapy study. Diabet Med. 2012;29(5):682-9.

7. Donnelly LA, Morris AD, Frier BM, et al. Frequency and predictors of hypoglycaemia in type 1 and insulin-treated type 2 diabetes: a population-based study. Diabet Med. 2005;22(6):749-55.

8. Garber AJ. Hypoglycaemia: a therapeutic concern in type 2 diabetes. Lancet. 2012;379(9833):2215-6.

9. Noh RM, Graveling AJ, Frier BM. Medically minimising the impact of hypoglycaemia in type 2 diabetes: a review. Expert Opin Pharmacother. 2011;12(14):2161-75.

10. The Diabetes Control and Complications Trial Research Group. The effect of intensive treatment of diabetes on the development and progression of long-term complications in insulin-dependent diabetes mellitus. N Engl J Med. 1993;329:977-86.

11. UK Hypoglycemia Study Group. Risk of hypoglycaemia in types 1 and 2 diabetes: effects of treatment modalities and their duration. Diabetologia. 2007;50(6):1140-7.

12. Miller CD, Phillips LS, Ziemer DC, Gallina DL, Cook $\mathrm{CB}$, El-Kebbi IM. Hypoglycemia in patients with type 2 diabetes mellitus. Arch Intern Med. 2001;161(13):1653-9.

13. Vexiau P, Mavros P, Krishnarajah G, Lyu R, Yin D. Hypoglycaemia in patients with type 2 diabetes 
treated with a combination of metformin and sulphonylurea therapy in France. Diabetes Obes Metab. 2008;10(Suppl 1):16-24.

14. Viberti G, Kahn SE, Greene DA, et al. A diabetes outcome progression trial (ADOPT): an international multicenter study of the comparative efficacy of rosiglitazone, glyburide, and metformin in recently diagnosed type 2 diabetes. Diabetes Care. 2002;25(10):1737-43.

15. Zoungas S, Patel A, Chalmers J, et al. Severe hypoglycemia and risks of vascular events and death. N Engl J Med. 2010;363(15):1410-8.

16. Cryer PE. Hypoglycaemia: the limiting factor in the glycaemic management of type I and type II diabetes. Diabetologia. 2002;45(7):937-48.

17. Fidler C, Elmelund CT, Gillard S. Hypoglycemia: an overview of fear of hypoglycemia, quality-of-life, and impact on costs. J Med Econ. 2011;14(5): 646-55.

18. Boussageon R, Bejan-Angoulvant T, Saadatian-Elahi $M$, et al. Effect of intensive glucose lowering treatment on all cause mortality, cardiovascular death, and microvascular events in type 2 diabetes: meta-analysis of randomised controlled trials. BMJ. 2011;343:d4169.

19. Budnitz DS, Lovegrove MC, Shehab N, Richards CL. Emergency hospitalizations for adverse drug events in older Americans. N Engl J Med. 2011;365(21): 2002-12.

20. Hammer M, Lammert M, Mejias SM, Kern W, Frier $\mathrm{BM}$. Costs of managing severe hypoglycaemia in three European countries. J Med Econ. 2009;12(4):281-90.

21. Honkasalo MT, Elonheimo OM, Sane T. Severe hypoglycaemia in drug-treated diabetic patients needs attention: a population-based study. Scand J Prim Health Care. 2011;29(3):165-70.
22. Ostenson CG, Geelhoed-Duijvestijn P, Lahtela J, Weitgasser R, Markert JM, Pedersen-Bjergaard U. Self-reported non-severe hypoglycaemic events in Europe. Diabet Med. 2014;31(1):92-101.

23. Henderson JN, Allen KV, Deary IJ, Frier BM. Hypoglycaemia in insulin-treated type 2 diabetes: frequency, symptoms and impaired awareness. Diabet Med. 2003;20(12):1016-21.

24. Akram K, Pedersen-Bjergaard U, Borch-Johnsen K, Thorsteinsson B. Frequency and risk factors of severe hypoglycemia in insulin-treated type 2 diabetes: a literature survey. J Diabetes Complicat. 2006;20(6):402-8.

25. Dornhorst A, Luddeke HJ, Sreenan S, et al. Safety and efficacy of insulin detemir in clinical practice: 14-week follow-up data from type 1 and type 2 diabetes patients in the PREDICTIVE European cohort. Int J Clin Pract. 2007;61(3):523-8.

26. Hermansen K, Dornhorst A, Sreenan S. Observational, open-label study of type 1 and type 2 diabetes patients switching from human insulin to insulin analogue basal-bolus regimens: insights from the PREDICTIVE study. Curr Med Res Opin. 2009;25(11):2601-8.

27. Luddeke HJ, Sreenan S, Aczel S, et al. PREDICTIVEa global, prospective observational study to evaluate insulin detemir treatment in types 1 and 2 diabetes: baseline characteristics and predictors of hypoglycaemia from the European cohort. Diabetes Obes Metab. 2007;9(3):428-34.

28. Dagogo-Jack SE, Craft S, Cryer PE. Hypoglycemiaassociated autonomic failure in insulin-dependent diabetes mellitus. Recent antecedent hypoglycemia reduces autonomic responses to, symptoms of, and defense against subsequent hypoglycemia. J Clin Invest. 1993;91(3):819-28. 